\title{
Parasitos gastrointestinais e sanguíneos em cães. Risco para a adoção?
}

\author{
Mario Luiz de la Rue*, Ariéli de Andrade ${ }^{\star *}$, Lilian Varini Ceolin ${ }^{\star *}$, \\ Carina de Castro Gabriel**, Lis Schons Garrot ${ }^{\star *}$, Vanessa Correa da

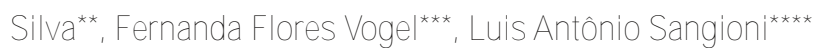

Resumo: Este estudo teve 0 objetivo de verificar a prevalência de parasitos intestinais e teciduais e estabelecer relação com zoonoses parasitárias por ocasião da adoção de cães errantes. Assim, coletou-se amostras de fezes e soro de 20 cães errantes sem prévio tratamento anti-parasitário, provenientes de cidades da região da Campanha do Rio Grande do Sul entre novembro a dezembro de 2007. Nas fezes foram encontrados ovos de Ancylostoma em todas as amostras (20/20) e Trichuris em $15 \%$ (3/20) das amostras. Coproantígenos de Echinococcus granulosus foram observados em $25 \%$ (5/20) das fezes. A imunofluorescência revelou 55\% (11/20) de prevalência para Toxoplasma gondii e $30 \%(6 / 20)$ de Neospora caninum Os resultados permitiram verificar que que a ingestão de formas parasitárias transmitidas por meio de carnes mal-cozidas (E. granulosus, $T$. gondii e $N$. caninum) é comum e que ovos de nematódeos que poderiam causar danos a seres humanos também foram identificados. Baseado nisto, pode se inferir que 0 ambiente endêmico permite a fácil contaminação com helmintos e protozoários. Sugere-se, assim que as pessoas encarregadas da adoção estabeleçam tratamentos eficazes contra todos os parasitos que possam infringir danos a saúde humana

Descritores: Cães Errantes; Adoção; Parasitos Gastrointestinais; Sanguíneos.

\section{Gastrointestinal and blood parasites in dogs. Risk for adoption?}

Abstract: This study aimed to determine the prevalence of tissue and intestinal parasites and establish a relationship with parasitic zoonoses at the time of stray dogs adoption. Thus, stool and serum collected samples from 20 stray dogs without prior anti-parasitic treatment, from towns in the Campaign region of Rio Grande do Sul State between November-December 2007. Ancylostoma eggs were found in all samples (20/20) and Trichuris in 15\% (3/20) of the samples. Coproantigens of Echinococcus granulosus were observed in 25\% (5/20) from the fecal samples. Immunofluorescence revealed $55 \%$ (11/20) prevalence of Toxoplasma gondii and 30\% (6 / 20) of Neospora caninum. Results showed that the ingestion of parasitic forms transmitted through poorly cooked meat (E. granulosus, T. gondii and N. caninum) is common and that eggs of nematodes that could cause harm to humans were also identified. Based on these aspects it could be inferred that the environment allows easy endemic infection with helminths and protozoa. It is suggested to the persons, responsible for adoption, to establish effective treatments against all parasites that may infringe human health damage.

Descriptors: Stray dogs; Adoption; Blood; Intestinal Parasites.

*Pós-Doutor em Helmintologia Animal pela Universidade Hohenheim, Alemanha. Professor titular da Universidade Federal de Santa Maria (UFSM), Santa Maria, RS, Brasil.

**Graduanda no curso de Medicina Veterinária pela Universidade Federal de Santa Maria (UFSM), Santa Maria, RS, Brasil.

***Doutora em Medicina Veterinária pela Universidade Federal de Santa Maria (UFSM), Santa Maria, RS, Brasil. Professor adjunto pela Universidade Federal de Santa Maria (UFSM), Santa Maria, RS, Brasil.

****Doutor em Epidemiologia Experimental Aplicada Às Zoonoses pela Universidade de São Paulo (USP), São Paulo, SP, Brasil. Professor Adjunto pela Universidade Federal de Santa Maria (UFSM), Santa Maria, RS, Brasil. 


\section{Introdução}

O estímulo a adoção de cães urbanos errantes tem sido intensificada por Organizações Não-Governamentais (ONG) que procuram conscientizar a população sobre seus benefícios, contrapondo a prática da eutanásia. Entretanto, a proximidade dos cães com os humanos representa um maior risco de ocorrência de doenças de caráter zoonótico ${ }^{1}$. Crianças em particular são altamente suscetíveis pelo íntimo contato com animais domésticos. Os ovos dos parasitos do gênero Trichuris² , de Ascarídeos e de Taenia são extremamente resistentes, representando assim um risco constante de re-infecção. Giardia, Cryptosporidium, Toxoplasma gondii e Neospora caninum também são considerados agentes infecciosos importantes ${ }^{3}$ assim como Toxocara canis causando larva migrans visceral e o Ancylostoma, responsável pela síndrome de larva migrans cutânea ${ }^{1}$.

A infecção de canídeos pelo gênero Echinococcus, causa nos hospedeiros intermediários ou acidentais, na forma larvar, a denominada equinococose cística e é uma zoonose de grande significado4,5. No Estado do Rio Grande do Sul o parasito tem como principais hospedeiros intermediários os bovinos e os ovinos, que asseguram a transmissão do helminto aos canídeos quando ingerem vísceras desses contaminadas com cisto hidático ${ }^{6}$. A infecção por T. gondii tem demonstrado prevalências variáveis, entre 20 e $91 \%$ entretanto, a toxoplasmose clínica em cães é rara, mas pode ocasionalmente ser encontrada em filhotes afetados por infeç̧ões congênitas, em cães com sistema imune deprimido ou associado a infecções concomitantes como 0 vírus da cinomose canina ${ }^{7}$. A neosporose clínica é muitas vezes vista em cães jovens afetados pela transmissão vertical. Os sinais clínicos são caracterizados por desordens neuromusculares devido a disseminação do parasita pelo sistema nervoso central e tecidos musculares ${ }^{7,8}$. Os cães são hospedeiros definitivos de Neospora caninum e a neosporose clínica é muitas vezes vista em cães jovens afetados pela transmissão vertical. Os sinais clínicos são caracterizados por desordens neuromusculares devido a disseminação do parasita pelo sistema nervoso central e tecidos musculares ${ }^{9,10}$.

Este trabalho teve como objetivo verificar a prevalência de parasitos gastrointestinais, Neospora caninum e Toxoplasma gondii em cães errantes provenientes da Campanha Gaúcha e alocados no Biotério Central da Universidade Federal de Santa Maria, Brasil. Além de avaliar as taxas de prevalência, procurou-se vincular sua importância com o risco que estas parasitoses poderiam oferecer aos humanos, principalmente por ocasião das adoções caninas.

\section{Material e métodos}

Foram analisadas amostras fecais e amostras de soro de 20 cães urbanos errantes provenientes de Dom Pedrito e Santiago, cidades da Campanha Gaúcha, de ambos os sexos e independente da idade, alocados no Biotério Central da Universidade Federal de Santa Maria entre novembro e dezembro de 2007. Estes animais continuaram neste local a

Saúde (Santa Maria), Ahead of Print, v.37, n.2, p. 75-80, 2011. Riscos para adoąão? disposição das necessidades didáticas da Universidade. As amostras fecais foram coletadas diretamente da ampola retal e acondicionadas em frascos individuais e armazenadas sobre refrigeração até o processamento laboratorial. As amostras de soro foram obtidas por punção da veia cefálica e alocadas em tubos sem anticoagulante. Imediatamente as amostras foram 
centrifugadas, sendo que o sobrenadante foi coletado e armazenado a $-20^{\circ} \mathrm{C}$ até a realização dos testes sorológicos.

As amostras foram processadas nos Laboratórios de Parasitologia Humana e de Doenças Parasitárias da mesma instituição. Nas fezes foi realizada a técnica de centrífugoflutuação para visualização de ovos de endoparasitos ${ }^{11}$ e ensaio de imunoadsorção enzimática (ELISA), conforme instruções do fabricante do "kit" (Chekit®), Bommeli Diagnostics, Suiça) para deteç̧ão de coproantígenos de Echinococcus granulosus. A leitura foi realizada em espectofotômetro para microplacas, obtendo-se os valores absolutos de absorbância em densidade óptica, e análise segundo as normas prescritas pelo fabricante. Já nas amostras de soro realizou-se o teste de imunofluorescência indireta (IFI) para detecção de anticorpos IgG para T. gondii e N. caninum empregando-se conjugado fluorescente anti-lgG canina (Sigma, EUA) ${ }^{12,13}$. O projeto foi analisado no Comitê de Ética em Experimentação Animal da Universidade Federal de S. Maria sob no 15/2007.

\section{Resultados e discussão}

Neste estudo, a percentagem de cães parasitados com ancilostomideos foi de $100 \%$ (20/20) (Tabela 1) o que pode ser justificada pela ausência de tratamento antiparasitário aos cães errantes e pela alta exposição aos parasitos a que são submetidos pelo fato de viver nas ruas. A presença de ancilostomideos em cães errantes já está bem descrita, apresentando variáveis taxas de prevalência como $17,1 \%^{14}, 34,8 \%^{15}$ e $22 \%{ }^{16}$. Os dados encontrados no presente trabalho foram superiores aos encontrados na literatura, mas esta variabilidade pode ser devida a condições ambientais (temperatura, umidade) além de fatores intrínsecos do hospedeiro como imunidade e condições alimentares ${ }^{17}$.

Em um estudo anterior houve uma prevalência de 9,7 \% (23/273) de Trichuris em amostras fecais de cães errantes da área central do Balneário Cassino, no Rio Grande do Sul, Brasil, sendo que a principal associação foi com o Ancylostoma $(16,9 \%)^{18}$. Dados semelhantes foram encontrados no presente trabalho (3/20), o que demonstra sintonia nas condições ambientais e fatores epidemiológicos. Apesar da presença de Giardia em cães ser comumente descrita na literatura, nenhum caso foi encontrado no presente estudo. Podem ter pesado para este aspecto a resistência adquirida pelos cães devido a sucessivas exposições e, também, ao baixo número de amostras examinadas ${ }^{19}$.

No único trabalho que relata a presença de coproantígenos de $E$. granulosus em cães urbanos errantes no Rio Grande do Sul ${ }^{6}$ foi relatada a prevalência de 10,8\% (7/65) de animais positivos. A alta prevalência, no presente trabalho, deste parasito $(5 / 20)$, poderia ser explicada, pela procedência dos cães, já que a região da Campanha Gaúcha, fronteiriça com o Uruguai e Argentina, constitui a área endêmica no Rio Grande do Sul20. Além disto, a amostra analisada neste trabalho (20 cães) poderia ter sido insuficiente para exata interpretação dos resultados, mas, evidencia que os animais ingeriram carne crua de hospedeiros intermediários. 
Tabela 1 - Prevalência de parasitos encontrados em 20 cães provenientes da região da Campanha no Rio Grande do Sul

\begin{tabular}{ccc}
\hline PARASITO & No de casos $^{\circ}$ & Porcentagem (\%) \\
\hline Ancylostoma & 20 & 100 \\
\hline Trichuris & 3 & 15 \\
\hline E. granulosus & 5 & 20 \\
\hline T. gondii & 11 & 55 \\
\hline N. caninum & 6 & 30 \\
\hline
\end{tabular}

Há muitos testes sorológicos que podem detectar anticorpos contra Neospora caninum sendo um deles a imunofluorescência indireta que é frequentemente usada. Estes testes sorológicos demonstraram que o parasito é encontrado em todo o mundo, com prevalências entre 0 e 31\%7,8,9, valores semelhantes ao do presente trabalho (30\%). Como o cão é considerado o hospedeiro definitivo, este propagaria os oocistos do parasito para 0 ambiente e seria uma fonte de infecção importante para os bovinos onde é um dos principais agentes de aborto. Até a presente data, não tem sido relatada a presença em seres humanos. ${ }^{21}$

Cães urbanos errantes tem anticorpos contra $T$. gondii, o que já foi evidenciado por vários trabalhos, ${ }^{22,23,24}$ com frequências variáveis (52, 46 e 50\%, respectivamente). No presente estudo foi encontrada uma frequência de $55 \%$ das amostras que apresentavam anticorpos anti $T$. gondii, utilizando a técnica de imunofluorescência indireta. Como se pode observar há uma considerável variação entre as freqüências de anticorpos anti T. gondii em cães, 0 que pode ser explicada pelo limiar positivo fixado para cada teste e conseqüentemente sua sensibilidade. Além disto, o tipo de alimentação disponível aos cães pode influenciar as taxas, já que, no presente caso, carne crua pode ser um dos componentes alimentares. Esta mesma fonte de alimentação poderia ser a fonte de infecção de N. caninum e $E$. granulosus o que justificaria as elevadas prevalências encontradas nestes animais.

Pela análise dos resultados pode-se concluir que existe uma gama grande de parasitos que infectavam os cães analisados. Estes podem ter sido encontrados devido a falta de tratamento antiparasitário e, também, pela alta exposição a patógenos tanto do solo como em carnes consumidas "in natura" Com isto ocorre uma fácil disposição desses animais à infecção parasitária. Mesmo que alguns dos patógenos encontrados não possam ser diretamente transmitidos a humanos, pode ser evidenciada a grande acessibilidade a infectarse e, provavelmente, a facilidade em se contaminar. Além disto, a partir dos dados encontrados na região analisada, a adoção de cães de procedência desconhecida deverá sempre ser precedida de um tratamento anti-parasitário amplo, que destrua não somente nematódeos intestinais, bem como outras formas passíveis de tratamento, como cestódeos e protozoários.

\section{Referências Bibliográficas}

Saúde (Santa Maria), Ahead of Print, v.37, n.2, p. 75-80, 2011. Riscos para adoacão? Riscos para adoação?
1. SANTOS FAG, YAMAMURA MH, VIDOTTO O, CAMARGO PL. Ocorrência de parasitos gastrintestinais em cães (Canis familiaris) com diarréia aguda oriundos da região metropolitana de Londrina, Estado do Paraná, Brasil. Ciências Agrárias 2007; 28(2): 257-268. 
2. KENNEY M, YERMAKOV V. Infection of man with Trichuris vulpis, the whipworm of dogs. Am. J. Trop. Med Hyg. 1980; 29(6): 1205-1208.

3. NEVES DP. Parasitologia Dinâmica. 3 ed. São Paulo: Atheneu, 2009.

4. DEPLAZES P, ECKERT J. Diagnosis of the Echinococcus multilocularis infection in final hosts. Applied Parasit. 1996; 37(4): 245-252.

5. NONAKA N, IIDA M, YAGI K., ITO T, OOI HK, OKU Y, KAMIYA M. Time course of coproantigen excretion in Echinococcus multilocularis infections in foxes and an alternative definitive host, golden hamsters. Int. J. Parasit:; 26(11): 1271-1278.

6. HOFFMANN NA, MALGOR R, DE LA RUE, ML. Prevalência de Echinococcus granulosus (BATSCH, 1768) em cães urbanos errantes do município de Dom Pedrito (RS), Brasil. Ciência Rural, S. Maria 2001; 31(5):843-847.

7. MINEO TWP, SILVA DOA, NÃSHUND K, BJÕRKMAN A, UGGLAA, MINEO, JR. Toxoplasma gondii and Neospora caninum serological status of different canine populations from Uberlândia, Minas Gerais. Arq. Bras. Med. Vet. Zoot. 2004; 56(3): 414-417.

8. MCALLISTER MM, DUBEY JP, LINDSAY DS, JOLLEY WR, WILLS RA, MCGUIRE AM. Dogs are definitive hosts of Neospora caninum. Int. J. Parasit. 1998; 28(9):1473-1479.

9. DUBEY JP. Review of Neospora caninum and neosporosis in animals. Korean J. Parasit. 2003; 41 (1): 116.

10. DUBEY JP, KNICKMAN E, GREENE CE. Neonatal Neospora caninum infections in dogs. Acta Parasit. 2005; 50(2): 176-179.

11. URQUHART GM, ARMOUR J, DUNCAN JL, DUNN AM, JENNINGS FW. Parasitologia Veterinária. 2 ed. Rio de Janeiro: Guanabara \& Koogan; 1996.

12. BERTSCHINGER B. Técnicas de Imunofluorescência e Análise Interpretativa dos Resultados. Porto Alegre: Ed. Autor, 1980

13. SCHARES G, PETERS M, WURM R, BÄRWALD A, CONRATHS FJ. The efficiency of vertical transmission of Neospora caninum in dairy cattle analyzed by serological techniques, Vet. Parasit. 1998; 80:87-98.

14. ALVES OF, GOMES AG, SILVA AC. Ocorrência de enteroparasitos em cães do município de Goiânia, Goiás: Comparação de técnicas de diagnóstico. Ciência Animal Brasileira 2005; 6(2): 127-133.

15. OLIVEIRA-SEQUEIRA TCG, AMARANTE AFT, FERRARI TB, NUNES LC. Prevalence of intestinal parasites in dogs from São Paulo State, Brazil. Vet. Parasit. 2002; 3:19-27.

16. VASCONCELLOS MC, BARROS JSL, OLIVEIRA CS. Parasitas gastrointestinais em cães institucionalizados no Rio de Janeiro, RJ. Rev. Saude Pub. 2006; 40(2): 321-323.

17. TAN JS. Human zoonotic infections transmitted by dogs and cats. Arch. Internal Med. 1997;157: 1933-43.

18. SCAINI CJ, DE TOLEDO RN, LOVATEL R, DIONELLO MA, GATTI FA, SUSIN L, SIGNORI VLM. Contaminação ambiental por ovos e larvas de helmintos em fezes de cães na área central do Balneário Cassino, Rio Grande do Sul. Rev. Soc. Bras. Med. Trop.2003; 6(5): 617-619.

19. BOWMAN DD, LUCIO-FORSTER A. Cryptosporidiosis and giardiasis in dogs and cats: Veterinary and public health importance. Exp. Parasit. 2010; 124(1): 121-7.

20. DE LA RUE ML. Cystic echinococcosis in southern Brazil. Rev. Inst. Med. Trop S. Paulo 2008; 50: 53-56.

21. MENEZES RCAA. Coccídeos. In: MONTEIRO S.G. Parasitologia na Medicina Veterinária, Roca, S. Saúde (Santa Maria), Ahead of Print, v.37, Paulo, 2011. p.141-157.

De La Rue, M. L., et al.

22. CABRAL DD, SILVA DAO, MINEO JR, FERREIRA FA, DURAN FP. Frequency of anti-Toxoplasma gondii 
antibodies in apparently healthy dogs of the city of Uberlândia - MG. Rev. Bras. Parasit. Vet. 1998; 7: 87-90.

23. DOMINGUES LM, MACHADO RZ, COSTA MT, CARVALHO CS, COSTAAJ, MALHEIROS EB. Canine toxoplasmosis: a comparative evaluation of the detection anti Toxoplasma gondii antibodies by the indirect immunoenzymatic assay (ELISA) and the indirect immnufluorescence reaction (IFI). Rev. Bras. Parasit. Vet. 1998; 7:79-85.

24. MEIRELES LR, GALISTEO JR, POMPEU E, ANDRADE JR. Toxoplasma gondii spreading in an urban area evaluated by seroprevalence in free-living cats and dogs. Trop. Med. Int. Health; 2004; 9(8) 876 - 881.

\section{Mario Luiz de La Rue}

Endereço para correspondência - Depto. de Microbiologia e Parasitologia, Prédio 20 Campus, Av. Roraima, 1000. Santa Maria, RS, Brasil.

CEP: $9715-900$

Email: mldelarue@hotmail.com

Currículo lattes: http://lattes.cnpq.br/5733736449142334

Recebido em 30 de junho de 2011.

Aceito em 26 de outubro de 2011. 